\title{
Preparation and Electrochemical Performance of a Honeycomb- like Porous Anode Material
}

\author{
Xin-xiu Li ${ }^{1}$, Jiao Hou ${ }^{2}$, Xing-wei Wang ${ }^{2}$, Xiong-fei Liu ${ }^{1}$, and Chun-ping Hou ${ }^{2, *}$ \\ ${ }^{1}$ China University of Mining and Technology Yinchuan College, Yinchuan Ningxia 750021, P.R. \\ China \\ ${ }^{2}$ Ningxia BOLT Technologies Co., Ltd., Yinchuan Ningxia, 750002, P.R. China \\ *E-mail: $\underline{\text { hcp400@163.com }}$
}

doi: $10.20964 / 2017.10 .08$

Received: 22 June 2017 / Accepted: 2 August 2017 / Published: 12 September 2017

\begin{abstract}
Ground coffee is used to prepare a honeycomb-like porous anode material for Li-ion batteries. The microstructure and morphology of the as-prepared samples are characterized by X-ray diffraction and scanning electron microscopy. The material has a honeycomb-like porous morphology, a smaller specific surface area than graphitized coke, and a relatively low degree of graphitization. Electrochemical tests show as-prepared anode material to have good low-temperature performance, large rate capability, and good cycling performance. At $-30{ }^{\circ} \mathrm{C}$, the material delivers a discharge capacity of $52.1 \mathrm{mAh} \mathrm{g}^{-1}$, which is more than three times that of graphitized needle coke artificial graphite anode material that is commercially available. Thus, it is suitable for high-power or energy storage batteries.
\end{abstract}

Keywords: Electrochemical performance; Coffee; Honeycomb-like; Li-ion batteries; Anode material

\section{FULL TEXT}

(C) 2017 The Authors. Published by ESG (www.electrochemsci.org). This article is an open access article distributed under the terms and conditions of the Creative Commons Attribution license (http://creativecommons.org/licenses/by/4.0/). 